\title{
SANTIAGO RAMÓN Y CAJAL, SU MUNDO A LOS OCHENTA AÑOS Y LOS SOLACES DE LA LECTURA
}

\section{Santiago Ramón y Cajal, his world seen at 80 and the joys of reading}

\author{
Elena GUARDIOLA iD; Josep-E BAÑOS \\ Facultad de Medicina. Universitat de Vic - Universitat Central de Catalunya. Vic (España). \\ Autor para la correspondencia: Josep-Eladi Baños. \\ Correo electrónico: josepeladi.banos@uvic.cat
}

Recibido: 29 de septiembre de 2021

Aceptado: 4 de octubre de 2021

No hay duda alguna de que el legado científico de Santiago Ramón y Cajal es extraordinario. Sus aportaciones al estudio anatómico del sistema nervioso, así como sobre su desarrollo y su patología son inconmensurables. Sus múltiples obras científicas han sido y siguen siendo obras de referencia.

Pero Ramón y Cajal dejó, además, otro legado escrito que incluye obras de ficción, así como numerosos ensayos y obras autobiográficas, un testimonio fundamental para comprender al científico y para conocer más aspectos sobre su manera de ser y de pensar, sus aficiones o su vocación pedagógica ${ }^{1,2}$.

En el último libro que escribió, poco antes de morir, y que tituló «El mundo visto a los ochenta años. Impresiones de un arteriosclerótico» ${ }^{3}$, Ramón y Cajal dice «En la presente obra pasaré revista, siquiera sea muy sucintamente, a las decadencias inevitables de los ancianos, singularmente de los octogenarios, agravados por achaques o enfermedades eventuales». Se trata de una obra en cierta forma autobiográfica, que consta de 21 capítulos y que el autor divide en cuatro partes: "Las tribulaciones del anciano», "Los cambios del ambiente físico y moral», "Las teorías de la senectud y de la muerte" y "Los paliativos y consuelos de la senectud». Cajal explica los inicios de su enfermedad y describe cuándo recibió el diagnóstico: "Fue hace unos trece años. De día en día notaba, al abandonar la tertulia del café, donde departía con los amigos acerca de todo lo divino y humano /.../, que mi cabeza ardía, sin que moderasen la sofocación el paseo ni el silencio absoluto. Cierto día, después de una sesión fotográfica a 35 grados, la 
congestión cerebral alcanzó tal agudeza que me obligó a consultar al sabio y simpático doctor Achúcarro, compañero de laboratorio. Me examinó y, previas algunas precauciones oratorias y eufemismos piadosos, lanzó el terrible veredicto: 'Amigo mío, ha comenzado la arterioesclerosis cerebral de la senectud. iNo hay que alarmarse! Estamos al principio y un buen régimen atajará el progreso del mal"3. Y le recomendó hablar y escribir poco, y abstenerse de lugares excesivamente calurosos: toda una tragedia ${ }^{4}$. Ramón y Cajal, con su excelente prosa, detalla a lo largo del libro cómo se siente, cómo evoluciona su enfermedad y cómo le cambia la vida: limita su vida social, deja de acudir a las tertulias... También habla de la pérdida de visión y del decaimiento de la función auditiva en la vejez, de la debilidad muscular, del insomnio y sus consecuencias, de lo que él llama «traiciones» de la memoria, de los cambios que ha visto durante su vida en las ciudades, en las costumbres y en las ideas políticas y de muchas otras cosas. Habla de deportes y de trenes, automóviles y aeroplanos («el delirio de la velocidad»), de cómo ven los jóvenes a los viejos y de la juventud "actual», de pintura, de fotografía, de la senectud y de la muerte, del ansia de inmortalidad... Pero no son estos los temas en los que vamos a detenernos en estas líneas, sino los que se relacionan con el lenguaje, la escritura y la lectura (incluimos citas textuales ${ }^{3}$, para no desaprovechar la ocasión de disfrutar de sus propias palabras).

Ramón y Cajal, en ésta su última obra, dedica un capítulo al lenguaje. El lenguaje, dice, «ha experimentado grandes y no siempre gratas transformaciones». Se refiere a "la manía de abreviar los apelativos», con especial referencia a las siglas («una enigmática sarta de charadas»). Se pregunta qué lengua se habla en España y responde «presumo que el castellano, mas salpicado e infestado con tantos barbarismos, solecismos y galicismos, que, si la Providencia no lo remedia obrando un milagro, acabaremos por convertir el idioma vernáculo /.../ en jerga o habla franca» y se lamenta de que «en vano la Academia y varios doctos filósofos y escritores de casta se esfuerzan por contener el alud arrollador de vocablos exóticos y neologismos superfluos». Sin embargo, reconoce que "fuera pueril desconocer que las lenguas evolucionan y que los inventos incesantes de las ciencias y de las artes nos imponen neologismos difícilmente reemplazables» que la Academia incorpora, aunque "concede hospitalidad en su diccionario a multitud de vocablos y acepciones de nueva y no siempre limpia acuñación» y añade una larga lista de palabras («ciertos dislates cometidos por muchos escritores noveles y singularmente por los tratadistas científicos») cuyo uso considera incorrecto y anima a que no se usen, aunque reconoce su "carencia total de autoridad para tan simpática empresa» y afirma «No me forjo ilusiones, empero, sobre la eficacia de estas prédicas». Dedica unos párrafos también a su uso en letreros y anuncios: «donde el prurito de importar a troche y moche voces extranjeras alcanza volumen desmesurado es en los letreros y anuncios». Son reflexiones de hace casi un siglo, pero, a nuestro entender, muchas siguen siendo completamente actuales ( $i$ !).

Cajal invita a escribir durante la vejez, sobre todo si ya se ha hecho antes, pero advierte que "hay muchos ancianos ansiosos de pensar y exteriorizar sus pensamientos, condensándolos en la letra de molde, sin detenerse a juzgar si son vulgares o interesantes, ni si están condenados al naufragio y olvido irreparables». Explica que él escribe por la mañana «... rodeado de una muralla de libros, entre los cuales abundan los diccionarios». Indica que, al escribir, lo mejor es continuar la labor emprendida en "los luminosos tiempos juveniles o en la fase de la madurez reflexiva, ya que así la tarea será más fácil».

Dedica Cajal los dos últimos capítulos a la lectura. "Redundante resulta encomiar la utilidad de los libros y el alto valor de los maestros del pasado. Precisa señalar más bien qué lecturas 
convienen a la senectud doliente y atribulada» dice, tras citar a distintos autores y el elogio que éstos hacen de la lectura. Comienza recomendando que el anciano no desconecte de la actualidad y lea diarios y revistas y, si tiene problemas de visión, busque quién se los lea, porque «Todo es preferible a la terrible incomunicación con el ambiente social, científico y político contemporáneos. Sin estas distracciones, la vida senil carecería de sabor». Además, concluye: «en el concierto de opiniones discordantes, es dable al anciano lanzar a veces una nota personal conciliadora /.../ puesto que está limpio de ambiciones y concupiscencias».

Sobre qué conviene leer, Cajal no duda: «el anciano necesita escoger sus lecturas con cuidadosa cautela» porque "atacado más o menos de insomnio y sujeto a cavilaciones enfadosas, necesita alimento espiritual suave y poco estimulante; que distraiga e informe objetivamente, pero sin impresionar sobremanera el ánimo con la evocación inoportuna de emociones melancólicas pretéritas». Ante esto, no se resiste a señalar qué obras deben ser prescritas y recomendadas para esta época de la vida. Nos muestra, además, el amplio conocimiento que tiene de la literatura española y extranjera, así como de los clásicos griegos y romanos.

En esta revista se han publicado interesantísimos artículos en los que se presentan listas de obras literarias, como los trabajos de Fernando A. Navarro ${ }^{5,6}$, que ofrecen una «breve visita guiada por esta biblioteca básica para médicos», en los que se presenta una lista esencial de obras literarias cuya trama gira en torno a la enfermedad, la locura, el hospital, el ejercicio profesional de la medicina o la figura histórica y social del médico. Y también artículos sobre la literatura de la enfermedad, obras en las que el enfermo convierte su enfermedad en una narrativa y cuenta su historia? ${ }^{7}$.

Las recomendaciones que da Cajal son de otro tipo, y aunque en algún momento se refiere a los médicos, se centra en las lecturas apropiadas en la senectud. Evita citar a los autores que le son contemporáneos, para no incurrir en olvidos o herir susceptibilidades. Los clásicos griegos y romanos encabezan su listado, porque son «el más sano y delicado manjar de los provectos». Incluye a Homero, Esquilo, Sófocles, Eurípides, Heródoto, Luciano y su autor favorito, Diógenes Laercio, que «relata todo lo que sabe de la vida de los filósofos /.../ y procede con admirable objetivismo». También Plutarco, de quien dice que escribe demasiado bien, aunque «es peligroso para leído por la noche» y Platón, admirable, en sus Diálogos y en la República, además de Aristófanes y los dramas de Esquilo, Sófocles y Eurípides («ciertamente pintan sucesos trágicos; pero en las páginas de los poetas lo dramático parece haber perdido sus toxinas»).

Entre los romanos, prefiere a Cicerón, que «cautiva instruyendo /.../ posee la virtud de no disgustarnos jamás y entretenernos siempre»; Plauto y Terencio son «un archivo de las costumbres y gustos romanos». Confiesa que sus gustos han cambiado con el paso de los años: «En mi calidad de caduco no me agradan ya las sabias y fúnebres prédicas del cordobés Séneca, antaño leídas con morosa delectación" y tampoco recomienda a esa edad a Epicuro y a Lucrecio («en la vejez suscitan resonancias harto melancólicas»). Destaca como sus favoritos a Virgilio y a Horacio («sus libros son un tesoro de buen sentido y de depurado gusto literario»), mientras que a Ovidio lo encuentra aburrido, excepto en su Metamorfosis. La lista es larga: Marcial, Cátulo, Propercio, Tácito, Suetonio, Julio César, Apuleyo, Tito Livio, etc., todos con sus correspondientes comentarios.

Dedica un amplio apartado a los clásicos españoles. Si las reflexiones y el listado de autores y obras griegos y romanos es enorme, al compararlo con el de los clásicos españoles, puede parecer corto, si bien incluye sólo una selección para los lectores de avanzada edad («libros excelentes, disertos, humorísticos o simplemente 
amenos y propicios a la ancianidad"): El Conde Lucanor, el Romancero, el Poema de Mio Cid, La Celestina, el Libro de buen amor, las poesías del marqués de Santillana y, sobre todo, las novelas picarescas (Lazarillo de Tormes, Estebanillo González, Marcos de Obregón, La pícara Justina...). Añade: «Estando nuestros clásicos en todas las bibliotecas de personas de buen gusto, fuera pesadez enumerar los mejores». Las obras de Quevedo, afirma, «constituyen la Biblia del anciano achacoso». De Cervantes recomienda Don Quijote, del que es mejor leer los episodios jocosos y evitar los relacionados con las desgracias del hidalgo, y las Novelas ejemplares. Sigue con los poetas del siglo de oro: Lope de Vega, Calderón, Ruiz de Alarcón, Góngora, Tirso de Molina, y con los prosistas, algunos posteriores: Saavedra Fajardo, Simón Abril, Huarte de San Juan, el padre Mariana, Baltasar Gracián, Argensola y Cristóbal de Villalón.

Refiriéndose ya a los siglos XVIII y XIX dice "son muy de recomendar, como sedantes de los arterioscleróticos», el Teatro crítico y las Cartas eruditas, de Feijoo, los discursos de Campomanes y Jovellanos, las comedias y traducciones de Moratín, las Memorias de un setentón de Mesonero Romanos, las obras de Zorrilla y las de Pérez Galdós, entre muchas otras. Dice, sin embargo, que prohibiría las melancólicas composiciones de Bécquer, de Espronceda y de Cadalso, entre otras composiciones "capaces de turbar el sosiego y la tranquilidad del ánimo del avejentado» porque, dice, «cada cosa a su tiempo y sazón». Recomienda también la lectura de las obras de Valera («maestro incomparable de la lengua castellana») y de Menéndez y Pelayo; aunque la obra de este último, por su intransigencia religiosa, "resulta un tanto perturbadora para la senectud, ansiosa de tranquilidad y ávida de sano y generoso patriotismo».

Reserva para el final un apartado que se supone sobre los libros extranjeros más convenientes para la vejez. Pero desiste del empeño y en vez de citar obras concretas, señala: «me contraeré a algunas recomendaciones de orden general y sin alusión a ninguna nacionalidad o escuela literaria». Distingue, como especialmente distraídas y atrayentes para el anciano, tres clases de publicaciones: los libros de viajes antiguos y modernos, como los periplos de los argonautas del mar y del aire; las narraciones con ilustraciones fotográficas de las maravillas de la historia natural y los tratados (modernísimos) de astronomía "que han revolucionado nuestra concepción del universo y extendido hasta límites inimaginables el espacio donde fulguran estrellas y nebulosas». Recomienda lecturas sobre las áreas en las que se ha estado ejerciendo durante la vida o de otras que puedan resultar interesantes. No hace falta que sean obras científicas, pueden ser de tipo divulgativo, en las que se desentrañen «los elementos de la teoría de la relatividad, la estructura del átomo, las propiedades de las diversas radiaciones, la arisca y enigmática doctrina de los Quanta y las admirables conquistas modernas sobre estrellas y nebulosas». Le gustan las biografías de hombres célebres y desaconseja al anciano «los libros de filosofía y de crítica religiosa, disconformes con sus íntimos anhelos e inveteradas convicciones» porque "acaso turben su tranquilidad y conmuevan sus esperanzas de ultratumba» y «a los setenta y cinco años, y mayormente, a los ochenta, las conversiones son imposibles; el cerebro ha cristalizado definitivamente en una estructura y una ideología invariables» ${ }^{3}$.

La vida de Cajal cambió radicalmente después del diagnóstico de su enfermedad. Dejó de asistir a su acostumbrada tertulia del Café Suizo, renunció a los largos paseos y a las excursiones, a los que era muy aficionado desde su juventud, y su actividad comenzó a limitarse, permaneciendo cada vez más en su domicilio. Pero a pesar de su estado de salud y de sus desánimos, Cajal continuó escribiendo y publicando de manera incansable durante las dos últimas décadas de su vida. A su prolífica producción científica, hay que añadir varias obras de diversos tipos, entre 
las cuales, la versión definitiva de sus memorias y una nueva versión de Charlas de café, que no estuvo exenta de críticas y comentarios. Publicó también, durante este periodo final de su vida, algunos textos sobre cuestiones relacionadas con la fotografía ${ }^{1}$.

A partir del fallecimiento de su esposa, en agosto de 1930, Cajal se encerró todavía más en sí mismo y, con el fin de aislarse del calor, habilitó como lugar de trabajo el sótano de su casa, en el que pasaba la mayor parte del día ${ }^{1}$. El mundo visto a los ochenta años, que subtituló Impresiones de un arterioesclerótico ${ }^{3}$ fue su último libro. Terminó de redactarlo a finales de mayo de 1934 y apareció cuatro meses después, coincidiendo casi con su muerte.

\section{Referencias}

1. López Piñero JM. Ramón y Cajal. Barcelona: Salvat Editores S. A.; 1995.
2. Collado-Vázquez S, Carrillo JM. Santiago Ramón y Cajal en la literatura, el cine y la televisión. Rev. Neurol. 2016; 63(10): 469-477.

3. Ramón y Cajal S. El mundo visto a los ochenta años. Impresiones de un arterioesclerótico. Madrid: Tipografía Artística Alameda; 1934. Se ha consultado la edición publicada en 1970: Ramón y Cajal S. El mundo visto a los ochenta años. Impresiones de un arteriosclerótico. Octava edición. Madrid: Espasa Calpe, S. A.; 1970.

4. Giménez-Roldán S. Demolición del palacete Ramón y Cajal y los últimos años del premio Nobel: la historia dilapidada. Neurosci. Hist. 2018; 6(1): 10-20.

5. Navarro FA. Biblioteca literaria para médicos (I). Rev. Med. Cine 2015; 11(2): 97-104.

6. Navarro FA. Biblioteca literaria para médicos (y II). Rev. Med. Cine 2015; 11(3): 163-172.

7. Cantabrana B, González-Rodríguez S, Hidalgo A. Una literatura de la enfermedad y de la muerte. Rev. Med. Cine 2016;12(1): 47-59.

Elena Guardiola. Doctora en Medicina. Investigadora asociada de
la Facultad de Ciencias de la Salud y de la Vida de la Universitat
Pompeu Fabra (2007-2018) y desde 2019 de la Facultad de Medi-
cina de la Universitat de Vic-Universitat Central de Catalunya, se
ha especializado en información, documentación y redacción cien-
tífica, áreas en las que ha impartido numerosos cursos. Su interés
por la relación entre la medicina y la literatura se ha plasmado en
la participación en varios proyectos así como en la publicación de
diversos trabajos.

